Correction

\title{
Correction to: "Corrosion Behavior Study of Aluminum Alloy 7075-T6 and 2A12-T6 Joints Prepared Using Friction Stir Welding”[Int. J. Electrochem. Sci., 15(2020)1072-1081; doi: $10.20964 / 2020.02 .03]$
}

Defeng Zhang*, Jun Xia, Qiuguo Yang, Tianhao Wei, Lijie Gong, Siyue She

School Of Materials Science and Engineering, Southwest Petroleum University, Chengdu 610500, China

*E-mail: 574285778@qq.com

Received: 23 November 2019 / Published: 30 November 2020

The authors regret that there were errors in the original published version

The author Defeng Zhang should be Defen Zhang. That should be corrected.

The correct paragraph is as follows:

Defen Zhang*, Jun Xia, Qiuguo Yang, Tianhao Wei, Lijie Gong, Siyue She

School Of Materials Science and Engineering, Southwest Petroleum University, Chengdu 610500, China

*E-mail: 574285778@qq.com

(C) 2020 The Authors. Published by ESG (www.electrochemsci.org). This article is an open access article distributed under the terms and conditions of the Creative Commons Attribution license (http://creativecommons.org/licenses/by/4.0/). 